\title{
Science education for all, some or just a few? Feminist and gender perspectives on science education: a special issue
}

\author{
Anita Hussénius
}

Received: 29 November 2013/Accepted: 29 November 2013/Published online: 8 January 2014

(C) Springer Science+Business Media Dordrecht 2014

This special issue of Culture Studies of Science Education has articles that adopt a critical stance by building on feminist, gender and/or queer perspectives on science education. Before a more detailed introduction and overview of the present issue, I will start by positioning gender studies and gender research, what it is and what it includes. Gender studies is an interdisciplinary subject emerging from feminist and critical research on gender and power issues, which comprises the knowledge of theories, methods and approaches from earlier and current feminist and gender research. Gender research is the study of gender and the intersection of gender with other socio-cultural categories of analysis and identity, such as ethnicity, sexuality, class, disability, nationality, language and more. It analyses the complex constructions of gender in different historical contexts, in various cultural arenas, and varying global processes. One aspect of gender research is feminist critique of the scientific knowledge production. Gender studies also includes other critical studies related to power and gender, such as women's studies, masculinity studies, and queer studies, among others. Thus, gender studies and gender research problematize the importance of gender in different contexts. At the focal point are questions such as: What are the explicit and implicit expectations of women and men in different social, cultural, and historical contexts? How is gender performed in daily life and practices? How do these norms and expectations limit the ways in which we are allowed to move, look, talk, behave, and learn? In this special issue the context is science education, including all levels from preschool to doctoral studies.

When the idea of a special issue arose, the intention from the beginning was to have a strong focus on feminist research. For some researchers, feminist research uses gender as an analytical category. For others, it has a specific meaning that is applicable to certain parts of the field and is characterized by including political activism and movement for social change. In that sense such research not only studies and problematizes the

Lead Editors: K. Scantlebury and A. Hussenius.

A. Hussénius $(\bowtie)$

Centre for Gender Research, Uppsala University, Box 527, 75120 Uppsala, Sweden

e-mail: Anita.Hussenius@gender.uu.se 
importance of gender in different contexts and settings, but always includes actions that promote a change towards a more equitable society. However, a point of departure for bringing about a desirable and necessary change is the knowledge and awareness of that something that needs to be changed. Research that applies gender theoretical perspectives may contribute to a deeper knowledge and understanding about power, hierarchies and inequities, thereby motivating and justifying actions for change. Thus, this special issue is not restricted to articles of feminist research in the sense of action, but contains a number of articles using gender and queer theories for analyzing science education. Moreover, this special issue also has articles that discuss other grounds connected to students' identities that influence their feelings of inclusiveness or alienation from science, such as social class, ethnicity, and sexuality.

\section{A need for feminist and gender perspectives in science education research}

Why is there a need for gender and feminist perspectives in science education research? Gender permeates societies, and is thus interwoven with natural sciences as subjects and interacts with students and teachers in a complex manner. The plethora of science subdisciplines often share a male dominant culture, which has been inherited from institutional environments that created them, including twentieth century universities and Cold War military (Schiebinger 1999). Because of its institutional history, gender patterns are still at work today even though there are rapid societal transformations that affect the sciences. Through the historically close connection between natural sciences and science education, which today are different fields of research and education, scientists have had a strong influence or even controlled what science education should include and what is important. While teaching addresses the scientific phenomena and concepts explicitly, it usually also convey an implicit message of what kind of practice science is and for whom it is available (Andree 2007).

The gender inequality of the science community (phrased for example as a "leaky pipeline") as well as the lack of interest from girls in science is a well-known challenge among scientists and science educators. During the last two decades, there has been a growing concern on the declining interest for science education and professions among youth in general and girls specifically, and their negative attitudes towards the natural science disciplines. Globally, students' lack of interest in science has been addressed in different, but still quite similar ways, with the aim of achieving a science education for all (e.g. Science and Technology for all in Sweden, Science for all Americans). The assumption has most often been that if girls/women only understood how exciting and interesting science is, they would freely choose these subjects. Instead, there is every reason to examine and question the science itself and its culture since so many students show disinterest in these disciplines and in different ways feel excluded from its practice. There is also research showing that teachers treat their students differently and have different expectations depending on whether they are girls or boys (Andersson 2012) and that teachers' assumptions and expectations impact their students' science achievement (Koch 2006).

For us, researchers with an interest in gender in science education and science activities, the importance of a gender perspective is obvious. We mean that a feminist science criticism offers a theoretical platform, an alternative way of looking at the sciences and science education, as a starting point to challenge the hypotheses and prevailing research practices in the field. Looking at the field of science education research and the main 
research topics within this field, gives at hand that this kind of research contributes only to a minority part of the whole, and what is obvious for us obviously is not that obvious for a majority of the researchers in the field. When science education researchers have studied gender as a category, they conceptualized gender as an individual trait, rather than from a social context (Nyström 2007) and many studies are restricted to comparing female and male students on variables such as students' achievement, participation, engagement, and attitudes towards science (Brotman and Moore 2008). Those who have placed attention on the relevance of gender issues in the teaching of science, often through a critical assessment of the subjects as such, have used different feminist theories as a starting point. However, these theories have only in a minority of cases been applied in empirical investigations of science educational contexts (Sinnes 2006).

Recently, in order to ascertain if gender is ignored in science education research, we conducted ERIC literature searches on the different phrases and topics that dominate the field. For each such "main topic" (e.g. conceptual change, nature of science, socio-scientific issues etc.) we added different descriptors (gender, feminist, equity) and conducted repeated searches. The investigation showed that very few peer-reviewed articles within science education research's main topics considered aspects of gender, feminism, or equity. The exception was the area "Design based and urban education" where $8.4 \%$ of the articles contained at least one of the descriptors. However, when 'gender theory or feminist critique' was included in the search with the other descriptors, in order to identify research that goes beyond using sex or gender as analytical categories without a gender theoretical background or analysis of power, the number of articles dropped dramatically (Hussénius, Andersson, Gullberg, and Scantlebury 2013). This special issue is thus a contribution to change the picture and increase the awareness of the importance of addressing gender issues within science education research.

\section{Female role-models}

Although the proportion of research with feminist and gender perspectives in science education is marginal in comparison to the areas that have dominated the field, there have been strong and insistent voices which in various ways have made themselves heard over the last several decades. Therefore, I am particularly pleased that two such "voices" of prominent and distinguished female researchers are given special attention in this issue of CSSE. Jane Butler Kahle's impressive engagement within science education makes her an outstanding key contributor of the field. Some of Jane's achievements include being Principal Investigator for more than fifty funded research and training grants, mentoring science educators, and conducting equity and science education work with numerous science teachers, school district personal and faculty. Especially relevant is that she has mentored, supported, advised and been a role-model for many female scholars in science education. An overview of her achievements is given by Kathryn Scantlebury in the article Jane Butler Kahle: Passion, determination, and vision. Another very important scientist and role-model is Sue Rosser, who embodies feminist studies of science. In this issue she contributes with a Forum piece and moreover, her latest book Breaking into the lab. Engineering progress for women in science is reviewed by Cathrine Hasse. Over the years Sue Rosser has strived to change science cultures, she has addressed the need for visualizing female scientists, their contributions and the barriers keeping them from progressing in science. In the book she shares her experiences as a female scientist, including documentation of different type of discriminations. 


\section{Transgressive encounters}

In 2006 the Centre for Gender Research at Uppsala University was appointed as a Centre of Gender Excellence by the Swedish Research Council. The name of the gender excellence programme is GenNa: Nature/Culture and Transgressive Encounters, and its aim is to maintain a research environment that promotes empirical investigations and theoretical reflections on the way gender and gendered knowledge is produced, in the borderland between the cultural and the natural sciences, and in the knowledge-producing interactions between empirical research, theory and teaching. Thus, researchers at the 'Centre' have their background in various disciplines and together they represent a great variety of competences and areas of specializations. Through trans-disciplinary efforts, events, and conversations, the Centre for Gender Research transgresses traditional organizational and knowledge boundaries and offers a unique and vibrant university wide meeting place for scholars and students in gender research.

The idea of a special issue of Culture Studies of Science Education on feminist and gender perspectives of science education was raised by Kathryn Scantlebury during her first stay at the Centre for Gender Research in Uppsala in the beginning of 2010. Since then Kate has returned several times, staying for shorter or longer periods, collaborating in research projects and participating in different activities. We share a common interest in gender/feminist science education and we have similar experiences from our chemistry backgrounds. The Centre for Gender Research is a research environment where transgressive encounters between cultural, social and biological understandings of sex and gender have become fundamental, something that is still quite unusual within the field of gender studies. Previously, there has been a profound mistrust between natural scientists and gender scholars, for example because of unwillingness in gender studies to address questions of nature, biology and sex (Holmberg 2008). Radically different views of nature, the construction of sex and the production of knowledge have isolated gender studies from the bulk of the natural sciences. In the Centre's profile today, researchers explicitly strive to overcome this mistrust and to create sustainable, productive collaborations across disciplines among researchers from these different domains. From this research environment Kathryn Scantlebury and I approached a number of scholars that we knew did research with a feminist, gender and/or queer perspective on science education and asked whether they were interested in contributing with papers in this special issue. Several Nordic scholars were approached and responded positively to this call, which is the reason for the preponderance of articles emanating from research conducted in the Nordic countries.

Over the last forty years, Nordic countries have become international leaders in gender equality and international scholars look to Scandinavia as a role model for gender equity. In the recent released World Economic Forum's Global Gender Gap Report (2013) Iceland continues to be at the top of the overall rankings for the fifth consecutive year. Finland ranks in second position, and Norway holds the third place in the overall ranking, while Sweden remains in fourth position. What is less known outside the Nordic countries is that the labor market in these countries remains highly gender segregated. Moreover, science in institutions of higher education is still lagging behind other sectors of the society (e.g. the number of women professors in the natural sciences is for instance still lower than in many other European countries). This is thus an area ripe for innovative approaches of issues that are debated in most countries and no longer possible to overlook. 


\section{Towards a more inclusive science education}

Feminist philosophers of science have criticized the sciences, pointing to a need for situating them historically and culturally, and made power imbalances visible, altogether leading to a critical examination of the practitioners as well as the disciplines themselves (see for example Keller and Longino 1996). As noted in this issue of CSSE, a problem that is often cited is the science subjects' elitist image and implicit messages of these subjects being particularly difficult and thus, requiring its participants to have a special talent. Such elitism becomes a barrier for engagement and this exclusionary practice primarily affects women, but also men. Teachers can consciously or unconsciously promulgate these beliefs and values, through their practices which can affect the teaching and the students. In other words, there is a need for an increased awareness that gender matters and that science is not a value-neutral subject.

A large portion of science education research focuses on students' difficulties with subject matter, and these problems are framed on an individual level. To illustrate that such problems can be more complex and actually not be restricted to an individual, I refer to a study by Schmader and Johns (2003). These researchers assigned a mathematical task to two groups. One of the groups, a 'control' group, was told by the researchers that they were going to work on a memory test. The other group, a 'test' group, was given the same information but was also told that underlying gender differences could account for different mathematical performances. After conducting the math test, there was no significant achievement difference between the sexes in the control group. However, in the test group, the women performed 40 percent lower compared to women in the control group, but the men's performance were not affected. The researchers concluded that the women in the test group experienced a "stereotypical threat", in this case quite subtle but even though with a dramatically negative effect on the women's mathematical performance. The implicit message perceived by women in the test group was that logical thinking is a masculine characteristic. It influenced the women and resulted in a physiological reaction, a brain stress. Just telling the test group that gender differences may impact performance, without mentioning how or in what direction, sent the message to the female participants that men are superior in mathematics.

By introducing critical perspectives in science education and thereby from an 'outside perspective' looking at the subjects, the culture, the activities as well as the science teaching may counteract students' alienation from sciences and have a positive impact on student achievement. Jill C. Sible, Dayna E. Wilhelm, and Muriel Lederman (2006) integrated feminist perspectives into a course in cell and molecular biology. They found that students' increased awareness of cultural aspects improved their knowledge, and in particular, female students performed better in tasks requiring logical thinking and problem solving, as compared to female students who completed a traditional version of the course. With these two closing examples as a background, it is my hope that the content of the present issue of CSSE will inspire research and activities that will contribute to a more inclusive science education.

\section{Overview of contributions}

The present issue of Culture Studies of Science Education contains three sets of papers organized around eight original manuscripts focused around the theme of feminist, gender and/or queer science education. The first set of papers, three articles and five forums, use 
different entrances to scrutinize science education more generally. In a feminist action research project with pre-school teachers, Kristina Andersson and Annica Gullberg use stimulated recall and other methods to challenge the participants' views of gender. In their paper, Andersson and Gullberg discuss possible ways of moving preschool teachers away from feelings of inadequacy and poor self-confidence in teaching science. They start by looking at one and the same science activity through two different theoretical lenses and thereby initiate an important discussion of the question, "What is science in pre-school?". In the two connected forum pieces, Christina Siry and Anita Roychoudery respectively respond to the main question from different perspectives and by doing so show the need for a continuing discussion. Since the problem with the lack of interest in science in many countries is addressed by introducing children to science through various activities at an increasingly early age, it is necessary to critically examine if the implementation of such initiatives are age appropriate. It is easy to fall in a trap of seeking for a "quick fix", to just apply the science teaching and the aim of science teaching for upper years to preschool children, or to suggest narrow and limited areas and activities as the sole solution. Hopefully more scholars in the fields of science education and early childhood education will be inspired to contribute with research and discussions of this issue.

In another study Carolyn Parker has followed eight Latina girls in an urbanized middleschool and from the girls' statements she concludes that the endeavor of science for all Americans is unsuccessful. In her paper she address how ethnicity and enrollment in English as a Second Language (ESOL) classes affect the academic expectations of these students, that they accept lower aspirations and stereotypifications because they implicitly receive messages from their teachers that their science learning and opinions are unimportant. Their school experience negatively impact their socio-academic science identities. Katherine Richardson Bruna takes a point of departure from Parker's examples of infantilization and passivation and frames her forum reflections within critical pedagogy and liberation theology, she broadens the discussion to an "urgent need for a critical reading of science literacy-what it means and for whom and how it is enacted by science teachers in classrooms to what effects for students". Moreover, in her response to Parker, she includes the aspect of class as one of the "multiple influences" at play in science instruction.

In their paper, Gendered education in a gendered world: looking beyond cosmetic solutions to the gender gap in science, Astrid Sinnes and Marianne Løken examine one of the largest Norwegian state initiatives to improve recruitment, retention, and gender equity patterns in STEM education and careers. They call for a cultural change in STEM and provide a feminist critique model to challenge recruitment and retention initiatives, and explore the idea of a gender-sensitive education to promote equality and justice. The forum by Karen Tonso underscores the pitfalls with inherent presumptions about individuals' STEM participation, such as biological givens or socialized dualities, which can function as a blinder and prevent the visualization and awareness of within-group diversity. In a second forum to the same paper Christine Forde on the other hand, scrutinizes the concept of gender-sensitive education and point to the risks of an imbalance between an individualcentered explanation ground and collective marginalization. Such an imbalance with a bias to individual differences, whether within a group or not, can result in gender-blindness masking structural marginalization. Whatever presumptions held-about biological givens or individual differences, this discussion reminds of the importance (as a teacher) to catch sight of one's personal beliefs and reflect upon the consequences (for students).

The second set of papers has two articles, the first by Auli Arvola Orlander and the second by Mattias Lundin, and two forums. Here biology education is the focus, and more specifically the hetereonormative sexual education in secondary school. In both 
papers, queer theories are used to elucidate what happens in the encounters between "basic facts" and relational issues in high school biology classes. The results illustrate the reconstruction of the hetero norm and the possible openings for discussions about alternative ways of viewing gender. Sue Rosser's forum response to Arvola Orlander's paper gives a short historical overview of the sexist bias of reproductive theory and sexual selection, represented in school text books and by biology teachers. She also provides examples of feminists' critiques that scrutinize dichotomies of male primacy over females, active sperm over passive eggs, heterosexuality over other sexualities and discuss pedagogical approaches to restructure existing norms. Using Lundin's paper, Inviting queer ideas into the science classroom. Studying sexual education from a queer perspective, Steve Fifield and Will Letts on the other hand address the complications of queer theories. They claim queering must not be only about sexuality or issues connected to sexuality, but want to open up for a queer critique of all science-its narratives, metaphors, analogies and facts. Moreover they illustrate queer complications with a twist, pointing to the risk of biting its own tail, that queer theories, along with the researchers who use these theories might find themselves caught up in a binary thinking about the heteronormative binaries that queer strives to dismantle. By reminding of the simultaneous affordances and limitations of binaries and binary thinking, they remind me of the dangers of using a narrow theoretical frame as a lens when interpreting empirical data. Altogether, these articles and forum pieces opens up for interesting discussions of importance for science education.

Finally, three articles and five forums concern physics students' identity constitution and positioning including aspects of gender and class at different levels of physics education, namely upper secondary school, undergraduate, and doctoral studies. Karin Due's study is conducted in an upper secondary school and uses video-recorded group discussions and individual interviews to extend earlier research that shows how the construction and reconstruction of images of physics and the skilled physics student, influence learners' feelings of being included or excluded in the practice of physics. Anna Danielsson explores how social class and gender intersect with the doing of physics in a case study where she has interviewed two male working-class, university physics students. Girls' and women's participation in physics and physics education have been problematized by others, because of the masculine connotation of the discipline. Danielsson's study is a valuable contribution since it challenges the often taken-for-granted notion that male physics students have an unproblematic relationship with their chosen discipline. Finally, Alison Gonsalves uses a sociocultural approach to examine women doctoral students' stories about becoming physicists. Both Danielsson's and Gonsalves' articles discuss enactments and competencies as important for being recognized as a legitimate physics participant, and make visible their informants' negotiations with themselves to fit into an expected physicist identity. Staffan Bergwik adds an historical perspective for understanding the situated learning and knowledge making of science, including the notion of belonging (and be-longing) as an "affective dimension" in production of one's own identity. He also discusses the importance of imitation when doing physics (and gender) in his forum response to Danielsson's paper. In another forum departing from Gonsalves' study, Helene Götschel stresses the aspects of diversity and contextuality of physics. Moreover, by giving examples of both how the scientific language reveals the gendered entanglement of physical knowledge, and how physicists historically have used concepts to argue for a hegemonic femininity, she broadens the aspects of making gender matter brought to the fore in this special issue of CSSE. 


\section{A chafing borderland}

Stated in the beginning of this editorial text, is the interdisciplinary characteristic of gender studies. Within an academic comparison it is a relatively new knowledge domain that has developed fast the last 40 years, and is still developing with high speed. It involves scholars from different fields, with different theoretical and methodological competencies, and with different cultural prerequisites. Science education research has similar interdisciplinarity perspectives. When science education researchers apply gender theories and/or gender scholars engage in science education research, it comes as no surprise that differing views of theoretical entrances and conflicting interpretations are foregrounded. This diversity, which is also visible in this issue of CSSE, can be looked upon as a chafing borderland. I use the metaphor chafing because it implies something that can cause irritation, but is also a practice that may smooth rough surfaces. As a chafing borderland this issue can inspire to new studies, continuing discussion and contributing to a necessary development of the field.

\section{References}

Andersson, K. (2012). It's funny that we don't see the similarities when that's what we're aiming forvisualizing and challenging teachers' stereotypes of gender and science. Research in Science Education, 42, 281-302. doi:10.1007/s11165-010-9200-7.

Andree, M. (2007). The lived curriculum: A study of science classroom practices in lower secondary school. Studies in educational sciences, 97, Stockholm University, HLS.

Brotman, J. S., \& Moore, F. M. (2008). Girls and science: A review of four themes in the science education literature. Journal of Research in Science Teaching, 45, 971-1002. doi:10.1002/tea.20241.

Holmberg, T. (2008). Discussions on biology: Gender scholars talk about bodily matters. Report: Crossroads of knowledge, Centre for Gender Research, Uppsala University.

Hussénius, A., Andersson, K., Gullberg, A., \& Scantlebury, K. (2013). Ignoring half the sky: A feminist perspective on the missing standpoints in science education research. In N. Mansour \& R. Wegerif (Eds.) Science education for diversity. Theory and practice. Rotterdam: Springer Publishing.

Keller, E. F., \& Longino, H. (1996). Feminism and science. Oxford: Oxford University Press.

Koch, J. (2006). Relating learning theories to pedagogy for preservice elementary science education. In K. Appelton (Ed.), Elementary science teacher education (pp. 91-106). New Jersey: Lawrence Erlbaum Associates Inc.

Nyström, E. (2007). Talking and taking positions. An encounter between action research and the gendered and racialised discourse of school science. Dissertations in Educational Work. Umeå University.

Schiebinger, L. (1999). Has feminism changed science?. Cambridge: Harvard University Press.

Schmader, T., \& Johns, M. (2003). Converging evidence that stereotype threat reduces working memory capacity. Journal of Personality and Social Psychology, 85, 440-452. doi:10.1037/0022-3514.85.3.440.

Sible, J. C., Wilhelm, D. E., \& Lederman, M. (2006). Teaching cell and molecular biology for gender equity. CBE-Life Sciences Education, 5, 227-238. doi:10.1187/cbe.05-08-0096.

Sinnes, A. (2006). Three approaches to gender equity in science education. NorDiNa, Nordic Studies in Science Education, 3, 72-83.

Anita Hussénius is Associate Professor in Organic Chemistry at the University of Gävle and Director of the Centre for Gender Research at Uppsala University, Sweden. She also coordinates the research program Nature/Culture Boundaries and Transgressive Encounters, the aim of which is to study empirically and reflect theoretically on the ways in which knowledge about gender and gendered knowledge are produced in the intersection between the natural and cultural sciences. Her main research interest is about gender perspectives on science education and more specifically, how an increased awareness of gender issues in science and in science teaching influences prospective teachers' identities as teachers and their teaching of science. 